\title{
Updated provisions of SANS 10160-4 for steel structures
}

\author{
C P Roth, A Gebremeskel
}

\begin{abstract}
A forthcoming revision of SANS 10160-4 (Seismic actions and general requirements for buildings) addresses the omission of structural steel design provisions from the standard, as well as contradictions between SANS 10160 and SANS 10162, the steel design standard. This note discusses the background to the proposed provisions.
\end{abstract}

\section{INTRODUCTION}

Basic provisions for the design of buildings and other structures to withstand earthquake loads have been available in the SANS codes since 1989. However, compliance with the requirements has not been vigorously enforced by the authorities and owners over the past two decades. This is largely due to lack of awareness by design engineers and academics. In some cases it has also been caused by skepticism about the level of seismic risk that exists in South Africa.

Despite having relatively low seismicity by global standards, South Africa has one of the most up to date codes in Africa when it comes to design for seismic resistance. Whereas the code addresses the design of concrete and masonry structures adequately, a gap exists when it comes to the design of structures that are framed in structural steel. Moreover, the fact that South African codes are derived from different code cultures, namely European and North American, at times causes confusion when attempting to design structures for seismic resistance.

Efforts have been made by the Southern African Institute of Steel Construction (SAISC), in collaboration with the South African Bureau of Standards TC98 to address the gap described above. The proposed provisions for the design of steel structures to resist seismic loading are expected to be published in a forthcoming revision of SANS 10160-4 (Seismic actions and general requirements for buildings). This note discusses the background to these provisions, for the benefit of practising engineers and future code developers.

\section{CURRENT CODE PROVISIONS}

Current seismic design practice allows structures to dissipate energy by nonlinear material behaviour during major seismic events. In order to avoid undertaking nonlinear dynamic analysis, the codes allow a designer to do a linear elastic analysis and reduce the resulting forces by a behaviour factor to reflect the energy dissipated by nonlinear behaviour. The value of the behaviour factor depends on the material type and structural system used. Structures with more inherent ductility and energy dissipation capacity have larger behaviour factors, which allow greater reduction in design forces.

The original SANS 10160-4:2010

(SANS 2010) and its first amendment SANS 10160-4:2011 (SANS 2011a) both allow a behaviour factor $q$ of 5.0 for ordinary braced steel frames, and 4.5 for steel frames in a moment-resisting frame system. No specific detailing requirements are specified other than "Detailing rules of SANS 10162-1 and SANS 10162-2 shall apply" and "Also refer to EN 1998-1 for detailing rules of structural steelwork." This is different to the situation for masonry and reinforced concrete structures, where higher behaviour factors are only allowed for structures complying with certain detailing requirements which are given in Annexes A and B. For example, the behaviour factor for a building frame system with reinforced concrete shear walls increases from 2.0 to 5.0 when specific detailing rules are applied. It is therefore inconsistent for the code to allow relatively high behaviour factors for steel structures without providing specific detailing rules for seismic design in SANS 10160-4.

This inconsistency was recognised when the original SANS 10160-4 was written. Wium (2009) identified quantification and confirmation of the behaviour factor for structural steel as a research need in his discussion of the background to the development of the original SANS 10160-4.

The Eurocode EN 1998-1 (EN 1998) allows behaviour factors in the range of 4.5-5.0 only for steel structures properly analysed and detailed in accordance with the requirements for "Dissipative structural behaviour". For steel structures where no specific detailing rules are applied, a value of 1.5 is recommended in Section 6 of EN 1998-1.

\section{TECHNICAL NOTE}

\section{JOURNAL OF THE SOUTH AFRICAN INSTITUTION OF CIVIL ENGINEERING} ISSN 1021-2019

Vol 59 No 1, March 2017, Pages 45-47, Note 75

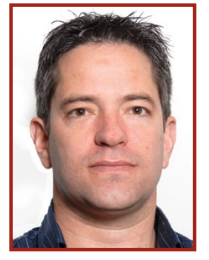

PROF CHRIS ROTH (Pr Eng, FSAICE) is Associate Professor in Civil Engineering at the University of Pretoria, working in the discipline of structural engineering. He started his career in consulting engineering before joining the University of Pretoria, and is the current chairman of SANS Technical Committee 98 Sub-committee 1 on "Basis of Design and Actions (including Earthquake Design)". He obtained a BEng degree in civil engineering at Stellenbosch University, and an MS and PhD at Cornell University. His interests are in structural reliability and structural analysis.

Contact details:

Department of Civil Engineering

University of Pretoria

Pretoria

0002

South Africa

T: +27124202185

E:chris.roth@up.ac.za

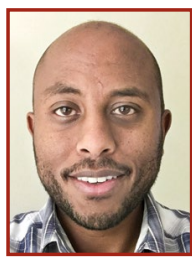

AMANUEL GEBREMESKEL (PE, SE) is registered as a Structural Engineer in the United States. He received degrees in Engineering and Business Administration from the University of Minnesota. He presently directs technical publications and research for the Southern African Institute of Steel Construction and chairs the SANS 10160-4 Seismic Sub-committee. He has been designing buildings and writing national codes in the United States and South Africa for the past 15 years.

\section{Contact details:}

Southern African Institute of Steel Construction

PO Box 291724

Melville

Johannesburg

2109

South Africa

T: +27117266111

E: amanuel@saisc.co.za 
SANS 10160-4 also contains no provisions for seismic steel support frames for heavy rigid objects, such as tanks, bins and similar containers storing liquids, gases and granular materials. These common structures are included in the scope of SANS 10160-4, which covers "industrial structures utilising structural systems similar to those of building structures". It was felt that provisions for seismic design of such structures would be beneficial.

\section{HARMONY BETWEEN CURRENT CODE PROVISIONS}

In addition to the omission of structural steel design provisions in SANS 10160-4 addressed above, there appears to be a contradiction between SANS 10160 and SANS 10162. The SAISC proposed modifications to both SANS 10160-4 and SANS 10162-1 (SANS 2011b) in order to resolve this contradiction while addressing the omission.

As stated previously, no specific detailing requirements are specified in SANS 10160-4 other than references to SANS 10162-1, SANS 10162-2 (SANS 2011c) and EN 1998-1. However, Clause 27 of SANS 10162-1:2011 refers the reader to Canadian standard CSA S16 (CSA S16 2014) for seismic design of steel structures. This contradiction has arisen because SANS 10162-1 is based on Canadian standards, while SANS 10160 is primarily based on European standards.

For steel structures where no specific detailing rules are applied, a behaviour factor of 1.5 is recommended in CSA S16. This value can be raised to 1.95 in some cases. These Canadian codes in turn rely on AISC 360/341/358 (AISC 360/341/358 2010) and the associated American standards ASCE 7 (ASCE 7 2010) (referred to as "ASCE 7" in the remainder of the note) and IBC (IBC 2015) to form the basis for their structural steel seismic design provisions.

ASCE 7 in turn allows the use of a behaviour factor of up to 3 for structural steel systems that are not specifically detailed to achieve high ductility. This level of confidence in the inherent ductility of typical steel structures is borne out by a century of experience in the western parts of the United States.

The dominance of American codes in general when it comes to seismic design can be attributed to the efforts of the Federal Emergency Management Agency in extensively collecting, analysing and standardising seismic response data over the past several decades. As such South Africa, Canada and Europe continue to look to American approaches and standards as a basis for their own standards.

\section{PROPOSED CODE FOR BUILDINGS}

The intention of the proposed code is not to provide steel detailing guidelines, but rather to deal more rationally with steel structures not specifically detailed for seismic resistance. A conservative option would be to use a behaviour factor of 1.5 in SANS 10160-4 for such steel structures, as recommended in EN 1998-1 and CSA S16. However, it is clear from the discussion above that such conservatism is not warranted when there is sufficient experience and data to support the more economical behaviour factors that are used in American codes such as ASCE 7.

Table 12.2-1 of ASCE 7 defines Response Modification Coefficients, Overstrength Factors and Deflection Amplification Factors for various types of structural systems. The Response Modification Coefficient is equivalent to the behaviour factor in SANS 10160-4. A value of 3.0 is given for "Steel systems not specifically detailed for seismic resistance, excluding cantilever column systems", for Seismic Design Categories B and C.

Cantilever column systems resist lateral forces solely by the columns acting as cantilevers supported at the base. Their exclusion in ASCE 7 is not relevant to the proposed code, as SANS 10160-4 Table 4 only includes braced and moment-resisting frames for steel structures.

To relate Seismic Design Categories B or C to SANS 10160-4 terminology, the clauses must be examined in more detail. Table 11.6-1 of ASCE defines the Seismic Design Categories in terms of Risk Categories I-IV and $S_{D S}$, the "design, 5 percent damped, spectral response acceleration parameter at short periods". In SANS 10160-4, $S_{D S}$ is equivalent to $S_{d}(T)$, $T_{B} \leq T<T_{C}$ with $q=1$, which is graphically the value of the flat portion of the design response spectrum in Figure 2. A structure in Risk Categories I-III falls under Seismic Design Categories B or C for $S_{D S}<0.50$, and a structure in Risk Category IV falls under Seismic Design Categories B or C for $S_{D S}<0.33$. These Risk Categories roughly correspond to the Importance Classes in Table 3 of SANS 10160-4. While there are some differences between classes II and III in the two codes, the distinction between I-III on one hand and IV on the other hand is the same in SANS 10160 and ASCE 7.

In seismic zone 1 as defined in SANS 10160-4, $a_{g}=0.1 \mathrm{~g}$ and the resulting $S_{d}(T)$ for $T_{B} \leq T<T_{C}$ is shown in Table 1 for the four different ground types. However, a more accurate comparison should include the effect of the redundancy factor $\rho$ of clause 7.4, which can be taken as 1.2. This minimum value of the factor was included to provide an additional factor to increase the seismic forces, as the specified value for $a_{g}$, $0.1 \mathrm{~g}$, is lower than the values on the latest seismic hazard maps (Wium 2010). Values of $\rho \mathrm{S}_{d}$ are also included in Table 1.

Table 1 Values of design spectral acceleration

\begin{tabular}{|c|c|c|}
\hline $\begin{array}{c}\text { Ground } \\
\text { type }\end{array}$ & $\boldsymbol{S}_{\boldsymbol{d}}$ & $\boldsymbol{\rho} \boldsymbol{S}_{\boldsymbol{d}}$ \\
\hline 1 & 0.25 & 0.3 \\
\hline 2 & 0.30 & 0.36 \\
\hline 3 & 0.29 & 0.35 \\
\hline 4 & 0.34 & 0.41 \\
\hline
\end{tabular}

It can be seen that if $\rho$ is excluded, the maximum value of $S_{d}$ is 0.34 , which is well under the 0.5 limit for classes I-III to fall in Design Categories B or C, and very close to the 0.33 limit for class IV. It may be argued that essentially all classes fall in Design Categories B or C, so the value of 3.0 suggested by ASCE 7 is applicable.

If $\rho$ is included, then the maximum value of $\rho S_{d}$ is 0.41 , so classes I-III still fall in Design Categories B or C. Class IV does not fall in Design Categories B or C, as 0.41 exceeds 0.33 .

As the emphasis in the SANS 10160-4 code is more on instilling correct structural concepts than on extensive calculations (Wium 2010), it was concluded that the vast majority of structures fall in Design Categories B and C, though possibly more consideration should be given to class IV structures that are founded on very loose soil and a lower behaviour factor should be prescribed in such cases. As a behavior factor of 3.0 is already more conservative and realistic than the existing code values, it was decided to adopt this value until more research on South African conditions becomes available.

With $q=3.0$, the inelastic displacement $d_{s}$ according to SANS 10160-4 clause 9.2 would be $0.7 q \times d_{e}=2.1 \times d_{e}$. From the Deflection Amplification Factor given in Table 12.2-1, ASCE 7 prescribes $3.0 \times d_{e}$. For consistency with ASCE 7 it is recommended that $d_{s}=3.0 \times d_{e}$ be specified in D.2.2 of the proposed code. The factor in ASCE 7 can be reduced by the redundancy and importance factors in certain cases, but it was felt that it is conservative and simple to leave it as 3.0.

Clause D.2.3 of the proposed code deals with elements that transfer load from floor or roof diaphragms to the vertical-lateral force resisting system and is based on clause 12.10.2 of ASCE 7, which requires "collector elements and their connections to vertical elements" to be designed for seismic forces including the Overstrength Factor, which is given as 3 in Table 12.2-1. Clause 12.10.2 of ASCE 7 applies 
to structures in Design Category $\mathrm{C}$, and not to Category B, but no distinction is made in the proposed code to keep it simple and conservative.

\section{SUPPORT STRUCTURES FOR HEAVY RIGID OBJECTS}

Guidelines for steel support structures for heavy rigid objects are included in clause D.3. They are based on section 15.3 of ASCE 7, "Non-building structures supported by other structures" from which the definition of rigid objects as "objects that have a fundamental period of less than $0.06 \mathrm{~s}$ and weigh over $25 \%$ of the combined weight of the object and supporting structure" is taken. Values of the Response Modification Coefficients, Overstrength Factors and Deflection Amplification Factors used in clauses D.3.2, D.3.3 and D.3.4 are from Table 15.4-2.

According to section 15.3.2, "The supporting structure shall be designed in accordance with the requirements of Chapter 12 or Section 15.5 as appropriate, and the $R$ value of the combined system is permitted to be taken as the $R$ value of the supporting structural system." The $R$ value obtained from Table 15.4-2 for "Elevated tanks, vessels, bins or hoppers" can cover the vast majority of support structures that are designed in South Africa.

Clause D.3.4 deals with connections between the object and the support structure and is based on section 15.7.3 of ASCE 7, with some modifications to the language to make it easier to follow in the SANS context. In ASCE 7 the factor by which forces are to be multiplied is given as the "overstrength factor", which is given as 2 in Table 15.4-2.

Clause D.3.5 deals with a heavy rigid object on grillage beams and is based on section 15.5.5 of ASCE 7, also with some modifications to the language to make it easier to follow.

\section{CONCLUSION}

A forthcoming revision of SANS 10160-4 addresses the omission of structural steel design provisions from the standard, as well as contradictions between SANS 10160 and SANS 10162, the steel design standard. The proposed revision is based on the ASCE 7 standard. Relevant parts of ASCE 7 have been adapted for the new SANS standard.

\section{REFERENCES}

AISC 341 2010. Seismic Provisions for Structural Steel Buildings. Chicago, IL: American Institute of Steel Construction.

AISC 358 2010. Prequalified Connections for Special and Intermediate Steel Moment Frames for Seismic Applications. Chicago, IL: American Institute of Steel Construction.

AISC 360 2010. Specification for Structural Steel Buildings. Chicago, IL: American Institute of Steel Construction.

ASCE 7 2010. Minimum Design Loads for Buildings and Other Structures. Reston, VA: American Society of Civil Engineers.
CSA S16 2014. Design of Steel Structures. Toronto, Canada: CSA Group.

EN (European Standard) 1998. EN 1998-1 2004. Eurocode 8: Design of Structures for Earthquake Resistance. Part 1: General Rules, Seismic Actions, and Rules for Buildings. Brussels, Belgium: European Committee for Standardization (CEN).

IBC 2015. International Building Code. Washington,

DC: International Code Council (ICC).

SANS (South African National Standard) 2010. SANS 10160-4: Basis of Structural Design and Actions for Buildings and Industrial Structures. Part 4: Seismic Actions and General Requirements for Buildings. Pretoria: SABS Standards Division.

SANS (South African National Standard) 2011a. SANS 10160-4: Basis of Structural Design and Actions for Buildings and Industrial Structures. Part 4: Seismic Actions and General Requirements for Buildings, Amendment 1. Pretoria: SABS Standards Division.

SANS (South African National Standard) 2011b. SANS 10162-1: The Structural Use of Steel. Part 1: LimitStates Design of Hot-Rolled Steelwork. Pretoria: SABS Standards Division.

SANS (South African National Standard) 2011c. SANS 10162-2: The Structural Use of Steel. Part 2: ColdFormed Steel Structures. Pretoria: SABS Standards Division.

Wium, J 2009. Background to the development of procedures for seismic design. In: Retief, J V \& Dunaiski, P E (Eds.), Background to SANS 10160. Stellenbosch: SUN Press, 167-188.

Wium, J 2010. Background to Draft SANS 20160 (2009): Part 4. Seismic loading. Journal of the South African Institution of Civil Engineering, 52(1): 20-27. 